\title{
Evaluation of Combined Heat Treatment Techniques of Testing Hardness and Tensile Strength of Mild Carbon Steel commonly used in Nigeria
}

\author{
${ }^{1}$ ADAMU, Y ; ${ }^{* 2}$ ADAMU, AA; ${ }^{1}$ SALIHU, Z; ${ }^{3}$ MUSA AB \\ ${ }^{I}$ Department of Physics, Ibrahim Badamasi Babangida University Lapai Niger State, Nigeria \\ ${ }^{2}$ Department of Mechanical Engineering, Bayero University, Kano, Nigeria; \\ ${ }^{3}$ Department of Welding and Fabrication Technology, Jigawa State Polytechnic, Dutse, Nigeria \\ *Corresponding Author Email:aaadamu.mec@buk.edu.ng
}

\begin{abstract}
This study investigated effect of combined heat treatment on the hardness and tensile strength of 0.25 - 0.35 grade of medium carbon steel. Heat treatment at $900{ }^{\circ} \mathrm{C}$ for four hours was done and six specimens of each were then quenched in water. Results showed that the hardness and tensile strength ranged from 113.7 to $184.4 \mathrm{HB}$ and from 383.84 to $621.2 \mathrm{~N} / \mathrm{mm}^{2}$, respectively, for hardening temperature from 700 to $950{ }^{\circ} \mathrm{C}$; and were from 180.2 to $125.5 \mathrm{HB}$ and 594.7 to $4143 \mathrm{~N} / \mathrm{mm}^{2}$, respectively, when the steel was quenched from $900{ }^{\circ} \mathrm{C}$ for tempering temperatures from 250 to $600{ }^{\circ} \mathrm{C}$. The result of tempering (from 250 to $600{ }^{\circ} \mathrm{C}$ ) when previously quenched (from $850{ }^{\circ} \mathrm{C}$ ) steel showed decreasing values of hardness (from 400 to $248 \mathrm{HB}$ ) and of tensile strength (from 1320 to $819 \mathrm{~N} / \mathrm{mm}^{2}$ ). The microstructure of the normalized sample was observed to be finer and more homogenized than the one observed in the as-rolled condition of the sample. This invariably led to the higher hardness and tensile strength values recorded.
\end{abstract}

\section{DOI: https://dx.doi.org/10.4314/jasem.v23i3.28}

Copyright: Copyright (C) 2019 Adamu et al. This is an open access article distributed under the Creative Commons Attribution License (CCL), which permits unrestricted use, distribution, and reproduction in any medium, provided the original work is properly cited.

Dates: Received: 17 November 2018; Revised: 19 January 2019; Accepted 22 January 2019

Keywords: Hardness, Tensile strength, quenching, microstructure, ferrite

It is a common fact that iron and steel are the key impetus that anchors the technological drive and development of any country. From the common appliances in our homes, through car manufacturing, ship building, houses and bridges, machineries in plants, locomotive parts and some intricate parts of space-ships, the application and use of iron and steel are quite visible in one way or the other. In a developing economy like Nigeria, the demand for steel production is high with very little local production because the steel rolling mills established by the federal government could not meet up with their mandates, being fraught as they were, with political, technical, logistical and managerial challenges (Ohimain, 2013). It is estimated that local production of steel can significantly reduce Nigeria's importation of steel and save Nigeria a minimum of US\$3billion dollars in foreign exchange per year (Vanguard, 2018). However, most of the imported steels are subject to scrutiny, as most of these steels are not able to withstand stress when subjected to load. Similarly, many different applications of steel for engineering purposes are largely due to the wide range of mechanical properties available by changes in carbon content. Many processes like spare parts manufacture depend heavily on the production of carbon steels and alloy steels because each component requires particular properties to perform its functions. Medium carbon steel has carbon content that ranges between $0.20-0.50 \% \mathrm{C}$ and it is a general-purpose steel for use where hardness, strength and wear resistance are important properties. The properties of steel are related to its structural make up; the mechanical properties can be influenced by altering the size, shape and distribution of various constituents (Hasan, 2015; Askeland et al, 2010; Fadare et al, 2011). This can be achieved practically by the process of heat treatment. According Tukur et al (2014), medium carbon steel in its tempered state, provides one of the best combinations of strength and toughness obtainable in medium carbon steels and that this makes tempering of martensite one of the most important heat treatments in modern steelmaking. Therefore, different combinations of time and temperature can give the desired mechanical properties during tempering, but temperature has the highest impact on tempering effect.

Therefore, it is important to know about the nature of austenite and its transformation on heating before proceeding on the heat treatment of metals. Heat treatment is basically the combination of operations involving the heating and cooling of a metal or alloy in solid state for obtaining required microstructures by 
refining the grain size, shape and distribution and a combination of properties (Rahman et al, 2016; and Białobrzeska, 2017). It is on this basis that carbon steel test treatment is of paramount importance and, hence, in this study some combinations of heat treatment procedures were employed as a means of testing the hardness and tensile strength properties of the carbon steel commonly used in Nigeria.

\section{MATERIALS AND METHODS}

Materials: The $0.25-0.35 \% \mathrm{C}$ grade of medium carbon steel used in this work was gotten as rolled and then made into hardness and tensile test specimens. The relevant equipment used are the heat treatment furnace; Brinell hardness testing machine; mounting press machine; Microscope and camera at the Centre for energy research Obafemi Awolowo University, Ile-Ife, Nigeria; the mounting press machine; belt grinder; roll grinder; universal polisher; microscope for scratch examination; and metallurgical microscope and camera.

Methods: For the heat treatment of the steel, the ASM (2014) Standard was used. For the harness and tensile strength testing, the ASTM E10-10 (2010) and ASTM E8 / E8M-16a (2016), were used, respectively.

Heat Treatment: Six specimens of $0.25-0.35 \% \mathrm{C}$ grade of medium carbon steel measuring $1 \mathrm{~cm}$ in height were used. They were cut from a steel rod using hacksaw according to the dimensions for hardness test and metallography experiment. These six specimens were then given the following heat treatment.

Hardening: The materials to be hardened were placed inside a metallurgical furnace with a capacity of 1,200 ${ }^{\circ} \mathrm{C}$ one after the other. The temperature intervals were $50{ }^{\circ} \mathrm{C}$. The furnace heating rate was $7^{\circ} \mathrm{C}$ per minute. The furnace was set to the required temperature, beginning from $700{ }^{\circ} \mathrm{C}$, and held at that temperature for 15 minutes until its colour coincided with that of the furnace wall. Then it was taken from the furnace and quickly quenched in water. The next specimen was heated to $750^{\circ} \mathrm{C}$ and held at this temperature for the same duration as the first, and hardened by quenching in water. The procedure was repeated for the third, fourth, fifth and the sixth specimen at temperatures of $800^{\circ} \mathrm{C}, 850^{\circ} \mathrm{C}, 900^{\circ} \mathrm{C}$, and $950^{\circ} \mathrm{C}$ respectively and quenched in water.

Tempering: Six specimens of the same dimension and chemical composition as the ones used above were placed inside the furnace and heated to a predetermined temperature of $900{ }^{\circ} \mathrm{C}$ and then held at this temperature for 15 minutes. They were then taken from the furnace and quickly quenched in water. The above six specimens, previously hardened at $900^{\circ} \mathrm{C}$ were again placed inside the furnace and were heated to predetermined temperatures of $250{ }^{\circ} \mathrm{C}, 300^{\circ} \mathrm{C}, 350$ ${ }^{\circ} \mathrm{C}, 400{ }^{\circ} \mathrm{C}, 500{ }^{\circ} \mathrm{C}$, and $600{ }^{\circ} \mathrm{C}$ respectively. Holding time was 15 minutes, after which they were brought out of the furnace and cooled in air.

Normalizing: The six specimens of the same dimension and chemical composition as the ones used above were placed in the furnace and heated to a predetermined temperature for 15 minutes. Then they were taken from the furnace and cooled in air. The six specimens were normalized at $850^{\circ} \mathrm{C}$, quenched from $900^{\circ} \mathrm{C}$ and were tempered at different temperature of $250{ }^{\circ} \mathrm{C}, 300{ }^{\circ} \mathrm{C}, 350{ }^{\circ} \mathrm{C}, 400{ }^{\circ} \mathrm{C}, 500{ }^{\circ} \mathrm{C}$, and $600{ }^{\circ} \mathrm{C}$ respectively.

Hardness and Tensile Strength Testing: The test pieces were cut from the steel rod of the same dimensions and chemical composition as the one used in the procedures described earlier. The surfaces were made plane so as to sit properly on the table. After the test pieces have been prepared for hardness test, the following procedure was then followed in order to determine the mechanical properties of the piece: (i) the tester was switched on from the rear and the LCD displayed the last test value. (ii) A black indenter (for diamond) was selected and was fixed correctly. (iii) The table spindle was unlocked and the work piece was placed on the table. The table was raised by the hand wheel until the indenter just touched the work piece. (iv) the correct gap between the indenter and the work piece was set and Brinell scale was selected. (v) Start bottom was pressed, "START LED" came on and the indenter moved towards the work piece, while LCD displayed "TESTING".

Tensile strength value was also determined from the hardness tester by pressing the tensile strength bottom. By this procedure and the following tests were carried out: (i) Hardness and tensile strength values of the specimen before any heat treatment. (ii) Hardness and tensile strength values after hardening. (iii) Hardness and tensile strength values after tempering (previously) quenched from $900^{\circ} \mathrm{C}$ ). (iv) Hardness and tensile strength values after normalizing. (v) Hardness and tensile strength values after Hardening (previously normalized at $80^{\circ} \mathrm{C}$ ). (vi) Hardness and tensile strength values after tempering (previously normalized at $850^{\circ} \mathrm{C}$ and quenched from $900^{\circ} \mathrm{C}$ ).

The Brinell hardness number $(\mathrm{HB}) \mathrm{kgf} / \mathrm{mm}^{2}$, as given by Engineering Toolbox (2008), was then calculated as: 
$H B=\frac{L}{A}=\frac{2 F(\mathrm{kgf})}{\pi D\left[D-\sqrt{\left.\left(D^{2}-d^{2}\right)\right]}\left(\mathrm{mm}^{2}\right)\right.}$

Where $L$ is load (kgf), $A=$ area of curved surface of indentation, $d$ is ball diameter $(\mathrm{mm}), D$ is diameter of circular indentation $(\mathrm{mm}) ; F$ is load, which, in hardness testing, has units of kilogram force (where $1 \mathrm{kgf}=9.81 \mathrm{~N})$.

The tensile strength was calculated using Equation (2):

stress $=\frac{\text { force }}{\text { area }}\left(\mathrm{N} / \mathrm{m}^{2}\right)$

\section{Microstructure Examination}

Mounting of Specimen: For proper holding for further operations like grinding and polishing to be carried out, the specimens were mounted inside plastic using mounting press. The specimens were placed with the outside surface on the mold ram of the mounting press one after the other. Phenolic powder was added and covered. Heater was placed on top of the cover such that heat penetrated and melted the powder which solidified on cooling, thereby, enabling a firm grip of the work piece. The mounted work piece was then ready for grinding. The mounted work piece was then readied for grinding.

Grinding: Rough grinding was carried out on a belt grinder which left the surface of the sample with scratches in only one direction. Fine grinding was done on a roll grinder with different grits $(240,320,400$ and 600). While moving from one grit to another, each specimen was turned through $90^{\circ}$. As the grit was changed to a finer one, scratches become less deep on the surface of the specimen after grinding.

Polishing: Universal polishers of two types were used, namely: Rough polisher, which uses Alpha micropolish of sizes 0.5 and 0.3 micro. The polishing was done by applying the polish on the rotary polisher; the machine was switched on and the work piece held tightly on it while it rotates. After 5 minutes on the first polish, it was changed to the second one. A micro-like surface was obtained with 0.05 micro polishes.

Microscopic Scratch Examination: A microscope of $100 \%$ magnification was used to examine the surface of the specimen after polishing so as to ensure that the scratches were completely removed.

Etching of the Specimen and Microscopy: The polished specimens were rinsed in alcohol and dried using an electric dryer. After which they were etched with $2 \%$ vital for 15 seconds. The specimens were then rinsed again in water and dried again. The etched specimens were placed on the metallurgical microscope one after the other for microstructure examination. Magnification of 500\% was used. The microstructure observed was photographed with the aid of the camera attached to the microscope.

\section{RESULTS AND DISCUSSION}

The results obtained from the hardness and tensile strength tests as well as metallography before and after various heat treatment of $0.25-0.35 \%$ carbon grade of medium carbon steel are shown in Figures 1 to 6, and in Plates 1 to 7 for the microstructure.

Hardness and Tensile Strength before Heat Treatment: Hardness and tensile strength values before heat treatment were: Brinell hardness (HB) $=113.9 \mathrm{HB}$; Tensile Strength $\left(\mathrm{N} / \mathrm{mm}^{2}\right)=383.6 \mathrm{~N} / \mathrm{mm}^{2}$.

Hardness and Tensile Strength after Heat Treatment

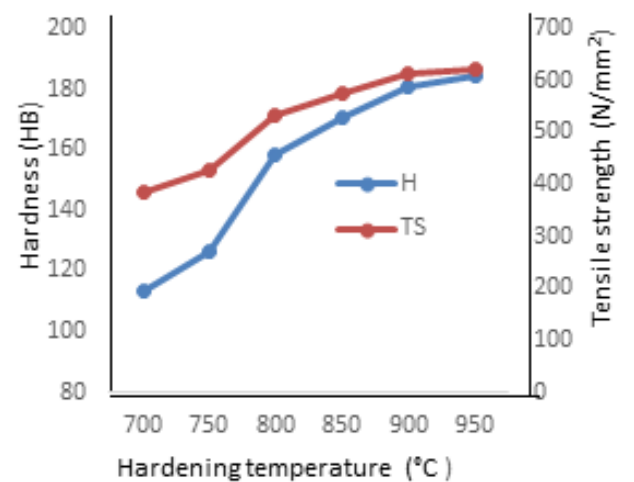

Fig 1: Effect of Hardening temperature on hardness and tensile strength without normalizing

Figure 1 shows the effect of increasing hardening temperature on the hardness and tensile strength. Both increased gradually with increasing hardening temperature from $113.9 \mathrm{HB}$ and $383.6 \mathrm{~N} / \mathrm{mm}^{2}$, respectively (for the as-rolled condition), to $184.4 \mathrm{HB}$ and $621.2 \mathrm{~N} / \mathrm{mm}^{2}$, respectively after hardening without normalizing, the increasing hardness making the steel more brittle.

For the same set of hardening temperatures as in Figure 1, Figure 2 shows the effect of normalizing on the hardness and tensile strength. It is seen that tempering at $850{ }^{\circ} \mathrm{C}$, further increased the hardness and the tensile strength, almost in identical proportion. However, between the hardening temperatures of 700 ${ }^{\circ} \mathrm{C}$ and $650{ }^{\circ} \mathrm{C}$, both the hardness and tensile strength were stabilized at about $160 \mathrm{HB}$ and $529 \mathrm{~N} / \mathrm{mm}^{2}$, respectively. 


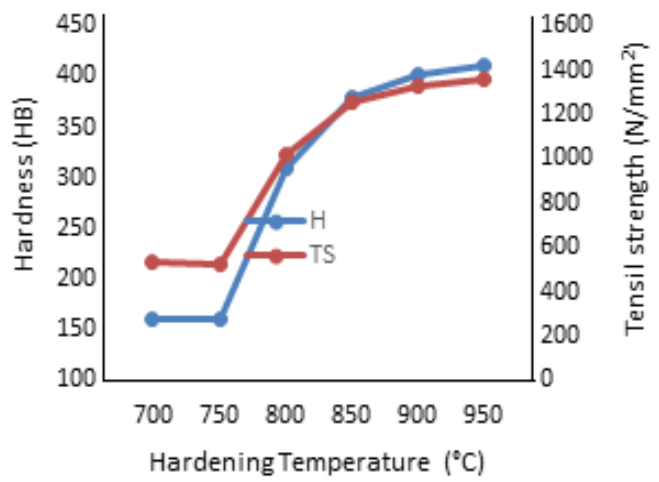

Fig 2: Hardness and Tensile strength at various hardening temperatures after normalizing at $850^{\circ} \mathrm{C}$

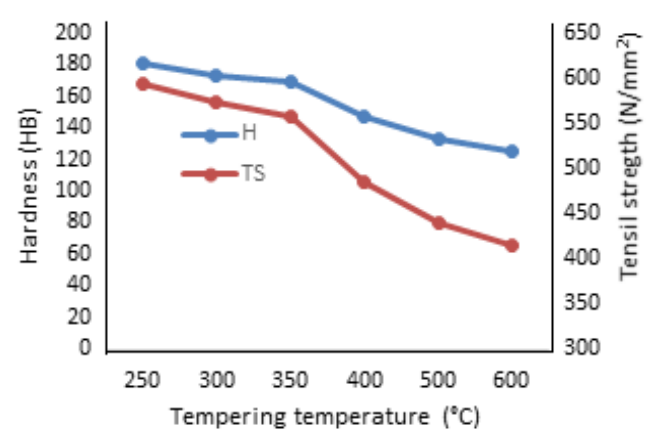

Fig 3: Hardness and Tensile strength at different tempering temperatures (previously quenched from $900^{\circ} \mathrm{C}$ )

The carbon steel was also tempered at varying temperatures after being previously quenching from $900{ }^{\circ} \mathrm{C}$ in water. Figure 3 shows that the effect of this was a gradual lowering of hardness and tensile strength from $180.2 \mathrm{HB}$ and $594.7 \mathrm{~N} / \mathrm{mm}^{2}$, respectively, at a tempering temperature of $250{ }^{\circ} \mathrm{C}$ to 125.5 $\mathrm{HB}$ and $414.2 \mathrm{~N} / \mathrm{mm}^{2}$, respectively, at a tempering temperature of $600{ }^{\circ} \mathrm{C}$. The later pair of figures still being higher than the values of the asrolled material. The result is consistent with the effect of tempering, which is normally used to relive internal stress, reduce brittleness (Hasan, 2015; and Rahman et al, 2016) and hence, tough to resist shock and fatigue. On the other hand, Figure 4 shows that when the carbon steel was normalized and quenched at $850{ }^{\circ} \mathrm{C}$ and then tempered at the same temperatures as in the preceding process, the hardness and tensile strength still reduced gradually from $400 \mathrm{HB}$ and $1320 \mathrm{~N} / \mathrm{mm}^{2}$, respectively at tempering temperature of $250{ }^{\circ} \mathrm{C}$ to $248.3 \mathrm{HB}$ and $819 \mathrm{~N} / \mathrm{mm}^{2}$, respectively, at tempering temperature of $600{ }^{\circ} \mathrm{C}$. The values of hardness and tensile strength at each tempering temperature in this case almost doubling the corresponding ones when tempered and only previously quenched at $900{ }^{\circ} \mathrm{C}-$ without normalizing.
The average values of hardness and tensile strength the steel in the normalized condition were $160.4 \mathrm{HB}$ and of $529.2 \mathrm{~N} / \mathrm{mm}^{2}$, respectively. The maximum hardness and tensile strength values obtained were $411.2 \mathrm{HB}$ and $1357 \mathrm{~N} / \mathrm{mm}^{2}$ respectively when quenched from $850^{\circ} \mathrm{C}$.

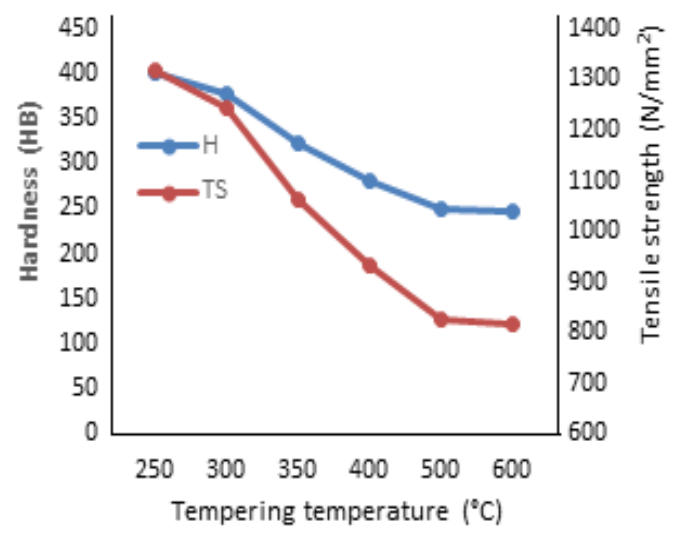

Fig 4: Hardness and Tensile strength at varying tempering temperatures (previously normalized and quenched at $850{ }^{\circ} \mathrm{C}$ )

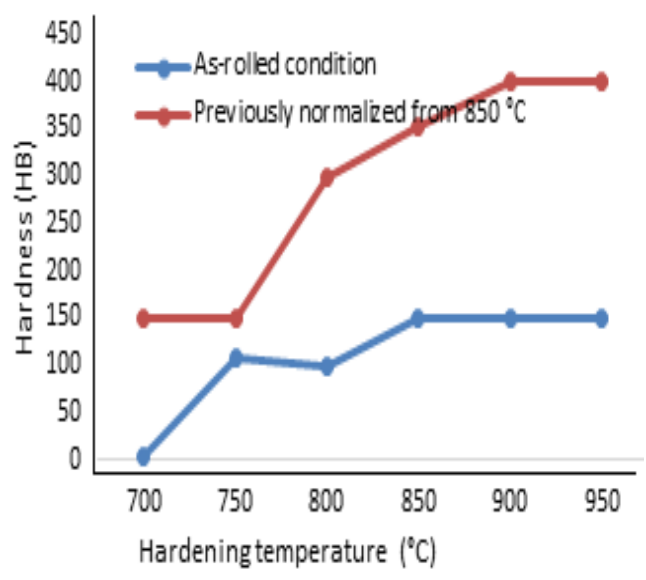

Fig 5: Hardness of the steel in the as-rolled condition and after normalization

The average hardness value $0.25-0.35 \% \mathrm{C}$ grade of medium carbon steel obtained was $113.9 \mathrm{HB}$ and its tensile strength was $383.6 \mathrm{~N} / \mathrm{mm}^{2}$ before heat treatment. As can be seen from Figures 5 and 6, both the hardness and the tensile strength increased. However, in the case of Figure 5, there was a little or no increase in hardness from hardening temperatures or $900{ }^{\circ} \mathrm{C}$ or higher. This is due to the fact that the grains were becoming course and the sample was getting decarbonized. Any further increase in temperature will cause a decrease in the hardness and the tensile strength. 


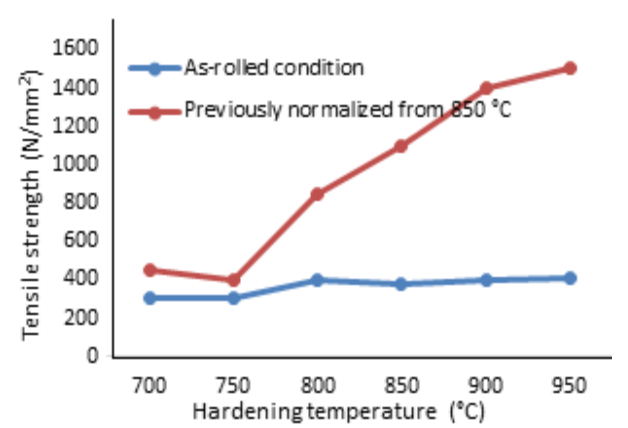

Fig 6: Tensile strength of the steel in the as-rolled condition and after normalization

The resulting increase in the tensile strength of the previously normalized (at $850{ }^{\circ} \mathrm{C}$ ) sample (Figure 6) can be accounted for by the formation of a finer and homogenized structure in normalized sample which served as a preparation for further heat treatment.

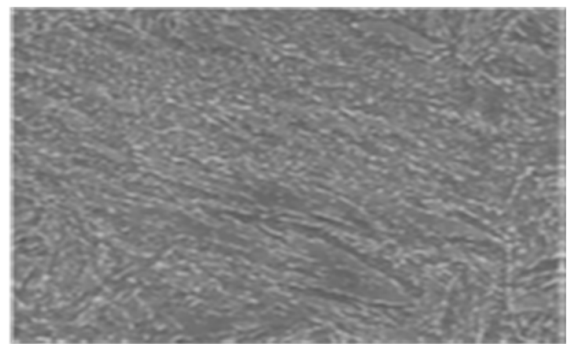

Plate 1: Distribution of tempered microstructure of $0.25-0.35 \% \mathrm{C}$ grade medium carbon steel quenched from $750{ }^{\circ} \mathrm{C}(500 \times)$

Microstructural Examinations: Plates 1 to 7 show the microstructure of the treated samples of steel.

Microstructure after Hardening: Plates 1 to 5 show that ferrite and pearlite have changed to ferrite and martensite on quick cooling. As heating temperature increase, the proportion of ferrite reduces while that of martensite increase accordingly. But at $900{ }^{\circ} \mathrm{C}$, the structure shows a fully martensitic structure (as shown in Plate 4).

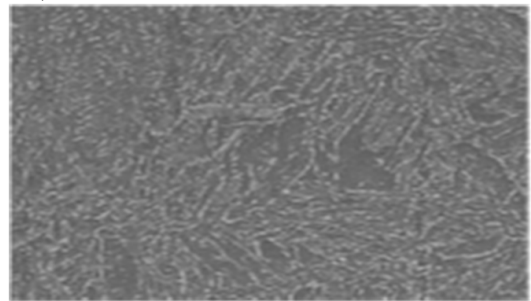

Plate 2: Distribution of tempered microstructure of $0.25-0.35 \% \mathrm{C}$ grade of medium carbon steel quenched from $800{ }^{\circ} \mathrm{C}$. $(500 \mathrm{x})$.

Formation of martensitic structure in cooling is responsible for the high hardness value obtained. It can also be observed that the black spots (non-metallic impurities) have been dissolved during the heat treatment. Martensite is observed as a mass of needle- like structures, which are very strong and hard, but very brittle, with the increase in hardness being attributable to the higher volume fraction of the harder martensite in the steel (Tukur et al, 2014).

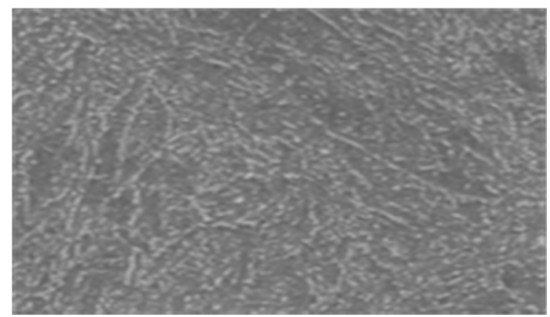

Plate 3: Distribution of tempered microstructure of $0.25-0.35 \% \mathrm{C}$ grade of medium carbon steel quenched from $850{ }^{\circ} \mathrm{C}(500 \times)$

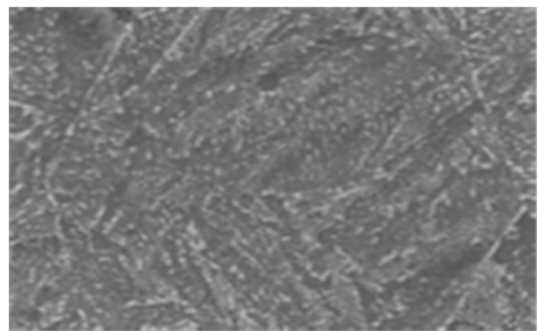

Plate 4: Distribution of tempered microstructure of $0.25-0.35 \% \mathrm{C}$ grade of medium carbon steel quenched from $900{ }^{\circ} \mathrm{C}(500 \times)$

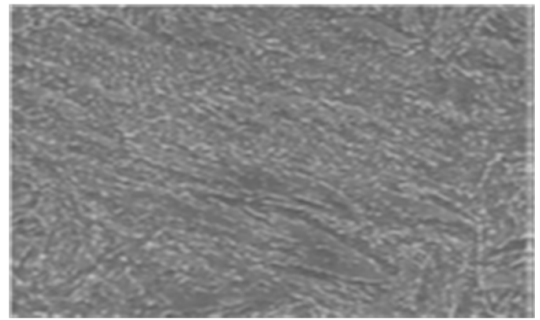

Plate 5: Microstructure of $0.25-0.35 \% \mathrm{C}$ grade of medium carbon quenched from $950{ }^{\circ} \mathrm{C}(500 \times)$

Microstructure after Normalizing: Plate 6 shows the microstructure after normalizing at $850{ }^{\circ} \mathrm{C}$. It can be observed that the pearlite structure present (dark inclusions) has become finer and the grain structure is homogenized.

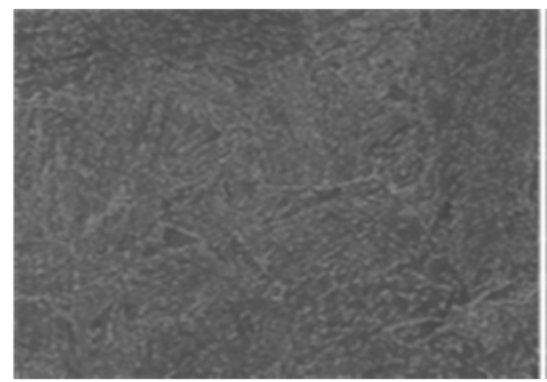

Plate 6: Microstructure of $0.25-0.35 \% \mathrm{C}$ grade of medium carbon quenched from $850{ }^{\circ} \mathrm{C}$ showing tempered lower bainite along with featureless bainite $(500 \times)$ 
The presence of finer pearlite structure is responsible for the increase in tensile strength and hardness value obtained as compared to the value obtained in the asrolled condition. When this specimen in the normalized condition was hardened at various temperatures, the pearlite was transformed to finer austenite which in turn transformed to finer martensite. This invariable led to high hardness and tensile strength values.

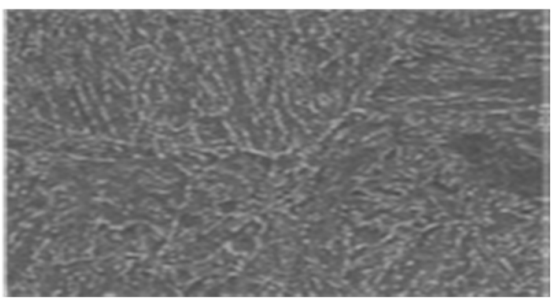

Plate 7: Microstructure of $0.25-0.35 \% \mathrm{C}$ grade of medium carbon steel tempered at $600{ }^{\circ} \mathrm{C}$ (previously quenched from $900{ }^{\circ} \mathrm{C}$ ), showing a full tempered martensitic structure $(500 \times)$

Microstructure after Tempering: Plate 7 shows the photomicrograph after tempering at $600{ }^{\circ} \mathrm{C}$ (previously quenched from $900{ }^{\circ} \mathrm{C}$ ). The hard, martensitic structure is observed transforming to the original pearlite structure. This is accounted for the reduction in hardness and tensile strength of the tempered specimens. Generally, the microstructure of the normalized sample was observed to be finer and more homogenized than the one observed in the asrolled condition of the sample. This also led to the higher hardness and tensile strength values recorded.

Conclusion: The effect of heat treatment on $0.250 .35 \% \mathrm{C}$ grade of medium carbon steel was investigated.

When the grade of the medium carbon steel was first normalized, hardened and then tempered, it possesses higher hardness and tensile strength values than when it was hardened and tempered from the rolled condition.

Tempering the previously normalized and quenched steel relieved the internal stresses and reduce brittleness. Therefore, since the hardened steel cannot be used directly because of brittleness, they can then be tempered at various temperatures (low and high temperature-tempering) after normalizing and quenching.

The microstructure of the normalized sample was observed to be finer and more homogenized than the one observed in the as rolled condition of the sample. This invariably led to the higher hardness and tensile strength values recorded.

\section{REFERENCES}

Askeland DR; Fulay, PP; Wright, WJ (2010). The Science and Engineering of Materials. Cengage Learning, Inc. Pp 31 and 39.

ASM Handbbok (2014). Heat Treatment of Irons and Steels. Dossett, EL; Totten GE (ed). Americn Society of Metals, Volume 4D

ASTM E8 / E8M-16a (2016). Standard Test Methods for Tension Testing of Metallic Materials, ASTM International, West Conshohocken, PA

ASTM E10-10 (2010). Standard Test Method for Brinell Hardness of Metallic Materials, ASTM International, West Conshohocken, PA

Białobrzeska, B; Konat, L; Jasi'nski, R (2017). The Influence of Austenite Grain Size on the Mechanical Properties of Low-Alloy Steel with Boron. Metals. 7(26): $1-20$

Engineering ToolBox (2008). BHN - Brinell Hardness Number. https://www.engineeringtoolbox.com/bhn-brinellhardness-number-d_1365.html [Accessed 18th November, 2018]

Fadare, DA; Fadara, TG; Akanbi, OY (2011). Effect of Heat Treatment on Mechanical Properties and Microstructure of NST 37-2 Steel. J. Minerals \& Materials Characterization \& Eng. 10(3): 299 308.

Hasan, MF (2016). Analysis of Mechanical Behavior and Microstructural Characteristics Change of ASTM A-36 Steel Applying Various Heat Treatment. J. Material Sci and Eng. 5(2): $1-6$

Ohimain, EI (2013). The Challenge of Domestic Iron and Steel Production in Nigeria. Greener J. Business and Management Studies. Vol. 3(5): 231-240

Rahman, SMM; Karim, KE; Simanto, MDHS (2016). Effect of Heat Treatment on Low Carbon Steel: An Experimental Investigation. J. Applied Mechanics and Materials. 860(7): 7 - 12

Tukur, SA; Usman, MM; Muhammad, I; Sulaiman, NA (2014). Effect of Tempering Temperature on Mechanical Properties of Medium Carbon Steel. Int. J. Eng.Trends and Tech. IJETT. 9(15): $798-800$.

Vanguard (2013). Reviving Nigeria's Steel Industry for Economic Development. The Nigerian Vanguard Newspapers. 